This item was submitted to Loughborough's Institutional Repository (https://dspace.lboro.ac.uk/) by the author and is made available under the following Creative Commons Licence conditions.

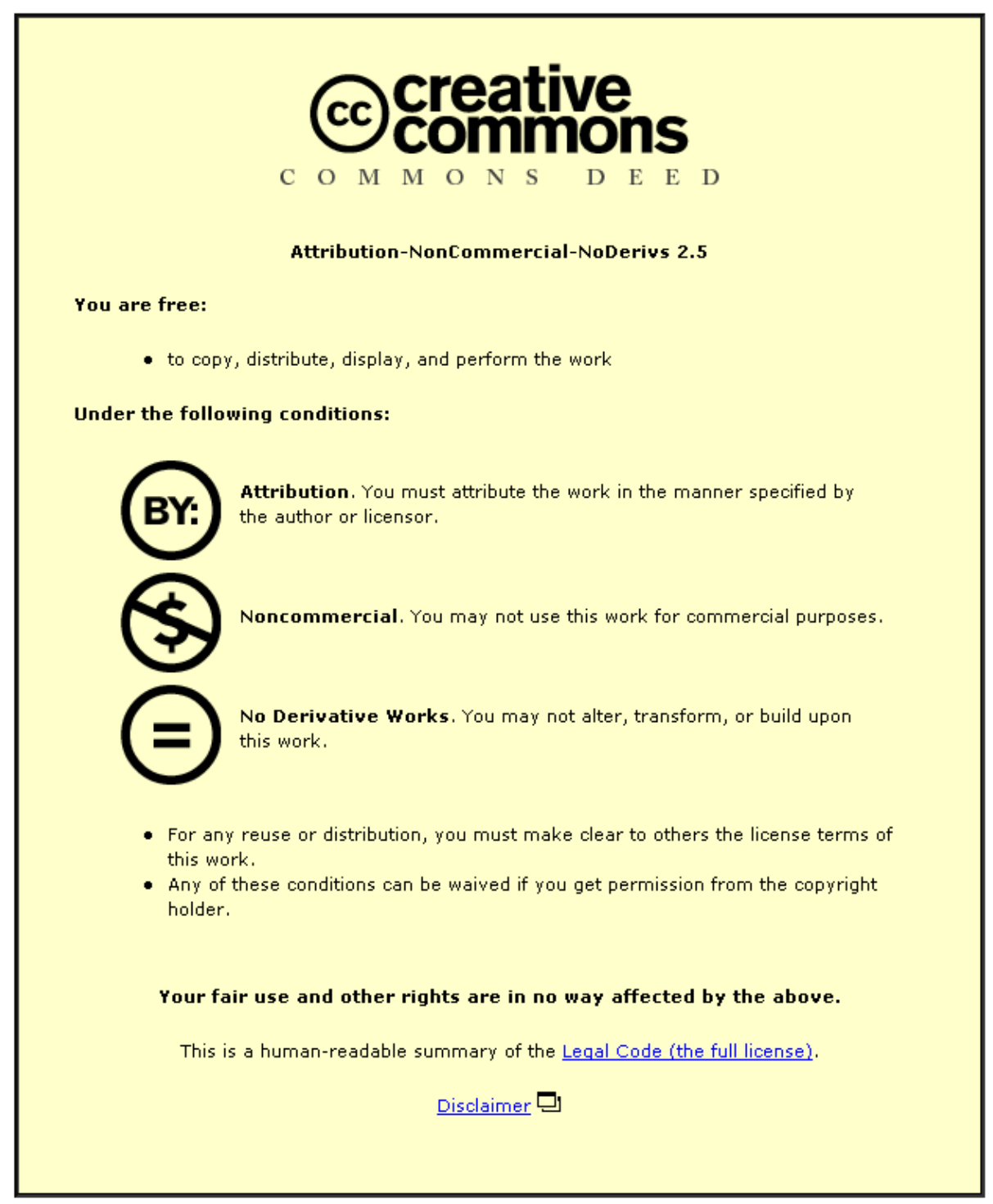

For the full text of this licence, please go to: http://creativecommons.org/licenses/by-nc-nd/2.5/ 


\title{
Learning about health through physical education and youth sport
}

\author{
Lorraine Cale and Jo Harris
}

\begin{abstract}
"Learning about health is crucial for the youth of today. If we can believe what we hear and read in the media, then most youngsters these days are unhealthy, inactive, overweight, and certainly less healthy, active and much fatter now than when we were young. They must be storing up a whole host of health problems. The thing is there are so many more opportunities for young people growing up today to be unhealthy and sedentary, what with the internet, computer games, fast food and all that. It's only right that we take the issues seriously and educate young people about health and healthy, active lifestyles. Besides, the National Curriculum requires us to." (Head of Physical Education in a secondary school)
\end{abstract}

The concerns and views expressed by the Head of Department here are typical of those of many physical education (PE) teachers today and they offer a convincing argument for teaching young people about health through PE and youth sport. At the same time, it is important to recognize that much of what is reported in the media about young people's health, activity and obesity levels is inaccurate, exaggerated and, therefore, misleading. This point is well made in the following chapter on 'Critical Health Pedagogies' and highlights the need to adopt a critical and cautious attitude towards contemporary health issues and messages. This is not to argue though that the very real health issues facing some young people can be ignored. 
The contribution that PE and sport can make to the health and well being of children and young people has attracted increased interest in recent years. With respect to PE, Shephard \& Trudeau (2000) consider the key goal of the subject to be the promotion of active, healthy lifestyles and Green (2002, p. 95) refers to the 'taken-for-granted role of PE in health promotion'. Furthermore, a number of Government policies and initiatives in England over recent years have identified PE and sport as instrumental in providing opportunities for young people to improve their health. A few notable examples include 'Game Plan' (Department for Culture, Media and Sport, 2002), 'Every Child Matters' (Department for Education and Skills, 2004) and 'Healthy Weight, Healthy Lives' (Department of Health and Department for Children, Schools and Families, 2008).

This chapter focuses on learning about health through PE and youth sport. The role that PE and youth sport play in promoting learning about health is initially explored, including consideration of the place of health within the PE curriculum in England. The latter part of the chapter then highlights some important issues relating to learning about health within both the PE and wider youth sport contexts.

Firstly though, it is important to clarify the terms PE and youth sport. PE takes place in schools during curriculum time, is statutory for all young people, and is delivered by trained PE teachers (or other appropriately qualified school staff). Youth sport, on the other hand, is participated in voluntarily by young people and can take place in a variety of contexts and be delivered by a range of individuals. For example, it may be delivered in schools, clubs, sports/leisure centres, or youth centres by coaches, volunteers, parents, youth workers or others. Thus, whilst there is a clear distinction 
between PE and youth sport, as acknowledged in chapter 1 and will become even more evident later on, there is much common ground between the two. Both represent key contexts for young people's learning about health through physical activity and sport and encounter some similar issues with respect to this area of learning.

The role of physical education and youth sport in promoting learning about health

The obvious contribution that PE and youth sport make to health is engagement in physical activity. Put simply, both provide opportunities for young people to be, and to acquire and develop the skills to be, physically active. It is commonly accepted that PE has the goal of educating about and through physical activity and sport, given its dual focus on 'learning to move' and 'moving to learn'. In this way, PE sets the foundation for lifelong participation in physical activity and sport (Association for Physical Education (afPE), 2008). A similar case could be made for the educational value of youth sport where coaches are interested in the holistic development of young people through sport. This educational function is important given mounting evidence of the health benefits to be gained from engagement in physical activity. Physical activity has been found to have a role in the prevention and management of overweight and obesity in young people, and there is good evidence of an association between physical activity levels and risk of type 2 diabetes and cardiovascular disease, and physical activity and bone health in children and adolescents (Stensel et al., 2008). Physical activity can also enhance self-esteem and cognitive function and reduce symptoms of depression and 
anxiety in young people (National Institute for Health and Clinical Excellence (NICE), 2007a; Stensel et al., 2008). The above is relevant given that a sizeable proportion of young people are known to be inactive and to lead relatively sedentary lifestyles (Cale \& Harris, 2005; McElroy, 2008).

There is also specific evidence to suggest that PE and youth sport can successfully contribute to the promotion of healthy lifestyles and learning about health. For example, school-based physical activity interventions, particularly those including some focus on $\mathrm{PE}$, have been reported to have a positive influence on young people's health, activity and fitness levels, as well as on their knowledge, understanding and attitudes towards physical activity (Cale \& Harris, 2006; Salmon et al., 2007). In addition, participation in structured and community youth sport has been found to have beneficial effects on the physical activity behaviours, lifestyles, and psychological well-being of young people (Brustad et al., 2008; Pate et al., 2000; Dzewaltowski, 2008). A further point to note regarding the contribution of PE in England is that, under the 2002 Education Act and the requirements of the National Curriculum, schools and PE have a statutory responsibility to promote learning about health to all young people. Details of the place of health within the National Curriculum in England are outlined in the following section.

Despite what has been said so far, and the sheer weight of evidence about the value of physical activity, it is also important to be realistic about what PE and youth sport can achieve in health given that they have a range of objectives and account for only a small proportion of young people's time. PE represents less than $2 \%$ of a young person's waking time (Fox \& Harris, 2003), at least half of which can justifiably 
involve only light or physically passive activity (Stratton et al., 2008) and, as already noted, youth sport is voluntary and it is neither available nor inclusive to all (Brustad et al., 2008; Dzewaltowski, 2008). The latest PE and Sport Survey in England revealed that an average of just $30 \%$ of youngsters participate in community sports, dance and multi-skill clubs (Quick et al., 2009). The need for youth sport programmes to reach more youth, become more inclusive (Brustad et al., 2008), and to build skills and assets for lifelong physical activity has been acknowledged (Dzewaltowski, 2008). Given these and other reasons which are explored later, the contribution of youth sport to learning about health is inevitably more limited and more variable in quality.

$P E$ and youth sport have an important role to play in promoting learning about health, but it is equally important to be realistic about what they can achieve.

Finally, it is important to be realistic about the numerous factors within and beyond the school and sport settings which influence children's health and physical activity levels, and to appreciate the complexities involved in changing health behaviours (NICE, 2007b). Tinning (2010) notes that it is unrealistic to expect individuals to change their lifestyles and behaviours simply because they acquire some new knowledge, and how to expect that knowing 'that', will translate into 'doing', is naïve (p. 181). Thus, whilst it is generally accepted that PE and youth sport, and particularly the former, have an important role to play in young people's learning about health, they clearly cannot (by themselves) meet all health and physical activity needs, nor be held responsible for improving the health and activity status of 
all children and young people. In short, improving health is a far more complex aspiration.

\section{Learning about health within the PE curriculum}

The association between health and PE is not new. Concerns about children's health and physical condition were instrumental in the introduction of PE into the education system in England, albeit in the form of prescribed exercises (Harris, 2010). However, by the end of the Second World War, a range of additional objectives for PE came to the fore. It was not until the 1980s that there was a return to health as a key objective of $\mathrm{PE}$, as 'a solution to the problem of improving the healthy lifestyles of children' (Tinning, 2010, p.177). In the UK, this renewed interest was expressed as 'health-related fitness' or 'health-related exercise', although other terms have also been adopted for this work. According to Harris (2010), these approaches attempted to broaden the traditional, competitive team-sport orientated programme in place at the time to include education about lifetime physical activity (i.e. activity that can readily be carried over into adulthood) and to introduce lifetime physical activities including fitness-related activities such as aerobics and circuittraining.

Since the 1980s, the emphasis and interest on health within PE has continued to flourish. The first National Curriculum for PE (NCPE) in England (1992) incorporated 'health' as a statutory component, but only as a theme to be embedded implicitly across a range of activity areas (e.g. athletics, games). This themed approach, however, was criticized for marginalizing health. Within subsequent revisions of the NCPE the health-related focus of the subject has arguably been strengthened (Fox \& 
Harris 2003; Cale \& Harris, 2005; QCA, 2007). In terms of the coverage of healthrelated issues within the current secondary NCPE in England, for instance, 'healthy, active lifestyles' is a key concept and 'making informed choices about healthy, active lifestyles' and 'developing physical and mental capacity' are key processes.

Furthermore, 'exercising safely and effectively to improve health and wellbeing, as in fitness and health activities' represents one of the six areas within the 'range and content' from which teachers should draw when teaching the key concepts and processes.

The place of health within PE has been strengthened over the years. Most would consider this to be good news but do you foresee any potential challenges with this?

\section{Issues}

The contribution that PE and youth sport can (and in the case of PE must) make to learning about health has been outlined. In theory, this may seem quite straightforward and achievable, however, in practice there are a number of issues which makes the reality quite different. A few of these have already been alluded to, but these and some other issues are now highlighted.

\section{Time and status}

Many countries around the world have witnessed a decrease in the time made available for PE in schools (Hardman \& Marshall, 2005) although, exceptionally, time for the subject in England has increased in recent years (OFSTED, 2005). But, more time does not necessarily equate to increased attention to health and it would seem 
that this has been the problem in England. Indeed, Ofsted reports in recent years (e.g. OFSTED, 2005; 2009) have consistently criticized the PE profession for marginalizing and paying insufficient attention to health, noting that this has led to weaknesses and confusion in many pupils' knowledge and understanding of the area.

In terms of the status of health, whilst PE teachers purport to value health and see this is an important objective of PE (Cale, 2000; Ward, 2009), there is evidence to suggest that their practice does not always reflect this. According to Green (2009), despite many teachers' philosophies incorporating several ideas or ideologies regarding the nature and purpose of $\mathrm{PE}$, including health, the most prominent theme is that of sport, with many viewing the subject as predominantly skill-centred and games-focused. Moreover, even when teachers make claims about the importance of health, sport is still seen as the main vehicle for achieving health goals (Green, 2009).

With respect to youth sport, it seems that the health philosophy issue is exacerbated. Dzewaltowski (2008) notes that the promotion of physical activity is not a primary goal of many organized sport community settings. Rather, and according to Brustad et al., (2008), youth sport tends to be very much bound by tradition, focusing more on skill development and competitive strategies and outcomes, and making it less responsive to current social trends and needs such as the need to promote a physically active lifestyle. 
In your view, should health be prioritized as an objective of PE and youth sport? Should both PE and youth sport be 'required' to contribute to learning about health?

\section{Focus and content}

It could be regarded as a major concern that although PE and youth sport represent ideal opportunities to educate children and young people about physical activity and health, contradictory philosophies concerning their role in health promotion hinder the development of effective health policy and practice. Indeed, a study of healthrelated exercise policy and practice in secondary schools in England and Wales found minimal change in the expression of health in PE over an 8 year period (Leggett, 2008). This reinforces earlier research findings suggesting that whilst many PE teachers articulate and value a 'fitness for life' philosophy, their delivery is usually oriented towards 'fitness for sports performance'. Further, this is linked to sport and fitness-related contexts that are often dominated by training and testing concepts (Harris, 1997; Leggett, 2008; Ward, 2009). Similarly, Green and Thurston (2002) have noted how an ideology of sport has penetrated deeply into the core assumptions of both PE teachers and government in relation to the promotion of health through PE.

At one level, the link between sport ideologies and health could be regarded as unproblematic, even 'natural', the concern, however, is that a sport focus which is based on competitive sports and team games has limited appeal for many children and young people (Green, 2002; Fox \& Harris, 2003). An over-emphasis on 'traditional (sport-based) PE' (Fox \& Harris, 2003) also results in a rather narrow 
curriculum with limited provision of a range of more recreational and individual lifetime activities and this may alienate some young people from the subject and possibly from physical activity participation beyond school and later in life (Stratton et al., 2008).

Similarly, whilst it could be argued that a fitness orientation with an emphasis on fitness activities and fitness testing is an acceptable part of learning about physical activity for health, this approach can be narrow, limited, and it too has been found to be unappealing for many children (Cale \& Harris, 2009). For instance, such a focus may lead to undesirable practices such as forced fitness regimes, directed activity with minimal learning, or dull, uninspiring drills, which are likely to be counterproductive to the promotion of healthy, active lifestyles in young people (Cale \& Harris, 2005).

The same argument has been leveled at youth sport with calls for youth and community sport to design and provide sport experiences that are effective and attractive to participants (Dzewaltowski, 2008). It is suggested that, despite adults involved in youth sport having good intentions, they do not necessarily provide an experience for children and young people that will facilitate their continued physical activity involvement (Brustad et al., 2008). Consequently, Brustad et al., (2008, p. 371) recommend that influential adults such as coaches and parents must help to establish a climate in youth sport in which lifelong health goals are valued. This would, of course, entail a corresponding de-emphasis on traditional competitive goals. 
Many activities traditionally offered through PE and youth sport fail to be attractive or appealing to many young people and do little to encourage their participation.

What can be concluded at this point is that establishing a solid foundation for continued engagement in physical activity is contingent upon young people learning about health in appropriate and supportive PE and youth sport environments. This, in turn, relies on practical, caring and inclusive teaching and/or coaching strategies which recognize and place young people's diverse learning needs and interests at the core. This point is made and firmly reinforced in chapter 1.

\section{Perspectives in learning about health}

The way in which learning about health is presented to young people is clearly critical to their experiences in, and understanding of, the area and there is some debate about the most suitable approach(es) to delivering health within the school curriculum. Traditionally, learning about health has had primarily medico-scientific, biophysical and psychological foundations and has been dominated by the ideology of healthism. This ideology is grounded in the belief that individuals have control over and should be responsible for their own health, leading to a pedagogy directed towards the transmission of prescriptive 'truths' or 'facts' about how we, as individuals, should live our lives (Tinning \& Glasby, 2002). From this perspective, 'not exercising' is viewed simply as a lack of motivation or just plain laziness on the part of the individual; a classic form of 'victim blaming'. It assumes individuals have the freedom to choose one set of lifestyle practices over another, and it underplays 
the social, cultural, emotional, economic or other factors that influence people's actions (Tinning, 2010).

More recently, and in response to critiques of the more traditional scientific and individualistic approaches, the sociocultural perspective to the delivery of health has emerged (Cliff et al., 2009) and is gaining increasing popularity. Cliff et al., (2009, p. 167) define this perspective as:

a way of examining health and physical activity issues that highlights social (power relations, political and economic factors, and dominant subordinate groups) and cultural (shared ways of thinking and acting such as ideas, beliefs, values and behaviours) aspects and influences.

The sociocultural perspective, therefore, moves beyond viewing health as personal responsibility. Drawing on knowledge from sociology and cultural studies, this approach takes into account the social and cultural environments and circumstances in which individuals act. Working from this perspective, a teacher would ask questions about the place of physical activity in people's lives, highlighting the sociocultural circumstances (e.g. location, cost, cultural background) which could influence engagement in physical activity.

At a deeper level, the sociocultural perspective is generally understood as part of a broader student-centred, inquiry based approach to education and learning that also encompasses problem solving and critical enquiry (Wright, 2004). This approach requires teachers to be facilitators rather than traditional experts, given that much of 
the knowledge around health can be regarded as 'grey' (Macdonald \& Hunter, 2005). For many PE teachers, however, given their scientific backgrounds and tendency to rely on 'facts', adopting such an approach can be something of a challenge. Yet, health is a complex issue requiring a broad approach that draws on knowledge in a wide range of domains; essentially, there are no easy solutions to health concerns and issues linked to physical activity.

Other approaches to health education in schools that have attracted increasing interest in England in recent years are whole school approaches such as Healthy Schools and the Active School (see for example, Cale \& Harris, 2005; Fox and Harris, 2003). Whole school approaches consider the role of the broader school environment in promoting learning about health, thereby making it a collective responsibility for teachers, students, parents, coaches and youth leaders (Stratton et al., 2008). These approaches can likewise overcome the limitations of traditional approaches and additionally they acknowledge the need to move beyond the 'restrictive, one-dimensional focus on traditional curricular physical education and sport' (Fox et al., 2004, p. 344) to recognize the multiple influences within and beyond the school environment which impact on young people's physical activity. For example, the influence of peers, family, and the 'hidden curriculum' in the form of policies and other practices (Cale \& Harris, 2005).

Due to the limitations of more traditional approaches to learning about health, the sociocultural perspective and whole school approaches are gaining support. 


\section{Health-related knowledge and professional development}

Chapter one introduced the three dimensional definition of pedagogy, identifying 'teachers/teaching and coaching/coaching' as the third dimension, alongside 'knowledge in context' and 'learners and learning'. This dimension recognizes how, to be effective, teachers and coaches need to be lifelong learners and take responsibility for 'growing' their expertise and knowledge. It is thus interesting to consider the expertise of those adults in PE and youth sport who are expected to deliver health and physical activity learning outcomes. Given that schools and PE also have a statutory responsibility to deliver learning about health it might be assumed that PE teachers at least have the knowledge, expertise and commitment to their own learning to effectively do so. But, evidence suggests that that this is not the case. A recent national survey of secondary school teachers in England revealed that health-related exercise had not been formally addressed within half of all teachers' initial teacher training, and over two-thirds of teachers had not participated in any relevant continuing professional development (CPD) in the previous three years (Ward, 2009). Similarly, evaluation of a recent national PE professional development programme found that the 'health-related modules' on offer were not selected by a high percentage of teachers (Armour \& Harris, 2008).

If such findings are representative, this leads to questions concerning whether and where PE teachers are acquiring the knowledge they need to enable them to effectively deliver learning about health. The answer seems to be that, at least for the majority, they are not. Research suggests that many PE teachers have a profound lack of knowledge in this area (Miller \& Housner, 1998; Castelli \& Williams, 2007). Castelli \& Williams (2007), for example, conducted a study which involved 
teachers taking a cognitive health-related fitness test (designed for $9^{\text {th }}$ grade students) and a self-efficacy questionnaire. Whilst the teachers were found to be 'over' confident about their health knowledge, with most thinking that they would pass the test, only just over a third actually did so.

This, as with other issues raised in this chapter, is of even greater concern in the context of youth sport. A much broader range of individuals contribute to the delivery of youth sport and their training is much more variable in depth and quality than that within the PE profession. Furthermore, given there is no comparable statutory 'requirement' to deliver learning about health through youth sport, it is likely that practice is variable. Indeed, Brustad et al., (2008, p. 354) note that 'coaches are typically hired because of their experience with the skills, techniques and competitive strategies of the sport and not for their knowledge about or interest in promoting physical activity for youth through sport.'

Evidence suggests there are limitations in the knowledge and professional development of those responsible for delivering learning about health through $P E$ and youth sport.

What is clear is that in both PE and youth sport, those charged with supporting young people to learn about physical activity and health need adequate initial and continuing professional development. It is a major concern that whereas this need has been identified with respect to PE teachers in the past (Cardon \& De Bourdeaudhuij, 2002; Cale, 2000), PE teachers tend not to recognize this need for themselves. Harris (2010) has argued that this may be due to their predominantly 
sports science backgrounds, leading PE teachers to believe that they know enough about health. Tinning (2010) has made a similar point, suggesting that university and college courses which prepare PE teachers have tended to be dominated by a traditional scientific perspective. Yet, it is argued that PE teachers' backgrounds in this respect do not sit particularly comfortably with, or suggest that they will have the knowledge and skills to work in the more flexible and student-centred ways advocated by the now more favoured sociocultural perspective.

\section{Conclusion}

It is clear that PE and youth sport have an important role to play in promoting learning about health and there is undoubtedly a growing interest and sound rationale for both to do so. That said, a number of issues are constraining the potential of PE and youth sport to effectively deliver this area, and there are concerns and/or confusion regarding teachers' philosophies/ideologies, and the focus, content and delivery of health. These are furthermore compounded by concerns over the limited health-related knowledge and professional development of those responsible for delivering learning about health. As chapter 1 highlighted, pedagogy is complex and three-dimensional, with 'knowledge in context', 'learners and learning', and 'teachers/teaching and coaches/coaching' all being key considerations in any learning context or episode. If PE teachers, coaches, and others working within PE and youth sport could be encouraged and supported to focus on all three of these dimensions when promoting learning about health, then they will be more likely to successfully engage more young people in a healthy, active lifestyle both now and in the future. 


\section{Learning tasks}

i) To date, what is your experience of learning about health through PE and youth sport? Can you recall ways in which teachers and coaches attempted to deliver health messages? Were they effective?

ii) Draw upon your personal experiences, views, and what you have just read to write a short narrative on 'How children and young people learn about health through PE and youth sport'. In doing so, consider the following questions:

- What role can, should, and does PE and youth sport play in promoting learning about health? Should the role be the same for both?

- What are some of the key issues associated with learning about health through PE and youth sport and why? Are there any other actual or potential issues?

iii) Read the following article which focuses on the promotion of healthy, active lifestyles through PE in the United States: McKenzie, T., L., \& Lounsbery, M.A.F. (2009). School physical education: The pill not taken. American Journal of Lifestyle Medicine, 3(3), 219-225. Then,

- Compare and contrast the profile of PE (including the issues raised) presented within this article with the one in this chapter. What are the main similarities and differences?

- Critique the authors' main arguments, views and recommendations. 
iv) A key resource providing further information on this topic is: Cale, L., \& Harris J. (eds). (2005). Exercise and Young People. Issues, Implications and Initiatives. Hampshire: Palgrave.

v) Group Task

As a group of teachers, governors, coaches or parents concerned about the coverage of health within a PE or youth sport context of your choice, prepare:

i) a case, and

ii) an action plan

for further strengthening the focus on learning about health within either of these contexts. Consider the issue by focusing on all three dimensions of pedagogy. Guidance

- From the perspective of one of the above groups, and for either PE or youth sport, argue the case (outlining why learning about health should be strengthened) and draw up a clear action plan (indicating how it will be strengthened).

- Try to anticipate any opposition to your case and plan, from who this might come (e.g. which groups/parties), and prepare suitable responses. The next chapter on 'Critical Health Pedagogies' may provide some further ideas in this respect.

- The case and plan might be presented as a written report, newspaper article, poster or oral presentation. 


\section{References}

Armour, K.M. \& Harris, J. (2008) Great Expectations...and Much Ado About Nothing? Physical Education and Its Role in Public Health in England. Paper presented at the American Educational Research Association (AERA) Annual Conference, New York, North America, March 2009.

Association for Education (afPE). (2008) Health Position Paper. www.afpe.org.uk/public/downloads/Health_Paper Sept08.pdf

Brustad, R.J., Vilhjalmsson, R., \& Fonseca, A.M. (2008) Organized sport and physical activity promotion. In A.L. Smith \& S.J.H. Biddle (eds.), Youth Physical Activity and Sedentary Behaviour. Challenges and Solutions (pp. 351-375). Leeds: Human Kinetics.

Cale, L. (2000) Physical activity promotion in schools - PE teachers' views. European Journal of Physical Education, 5, 158-168.

Cale, L. \& Harris, J. (2005) (eds.), Exercise and Young People. Issues, Implications and Initiatives. Hampshire: Palgrave.

Cale, L. \& Harris, J. (2006) School based physical activity interventions effectiveness, trends, issues, implications and recommendations for practice. Sport, Education and Society, 11(4), 401-420. 
Cale, L. \& Harris, J. (2009) Fitness testing in physical education - A misdirected effort in promoting healthy lifestyles and physical activity? Physical Education and Sport Pedagogy, 14(1), 89-108.

Cardon, G., \& De Bourdeaudhuij, I. (2002) Physical education and physical activity in elementary schools in Flanders. European Journal of Physical Education, 7(1), 5-18.

Castelli, D. \& Williams, L. (2007) Health-related fitness and physical education teachers' content knowledge. Journal of Teaching in Physical Education, 26(1), 3-19.

Cliff, K., Wright, J., \& Clarker, D. (2009) What does a 'sociocultural perspective' mean in health and physical education? In M. DinanThompson (ed.), Health and Physical Education. Issues for Curriculum in Australia and New Zealand (pp. 165182). Victoria: Oxford University Press.

Department for Education and Skills. (2004) Every Child Matters. London: HMSO.

Department for Culture, Media and Sport. (2002) Game Plan: A Strategy for Delivering Government's Sport and Physical Activity Objectives. London: DCMS Strategy Unit.

Department of Health and Department for Children, Schools and Families. (2008) Healthy Weight, Healthy Lives: A Cross-Government Strategy for England. London: HMSO. 
Dzewaltowski, D.A. (2008). Community out-of-school physical activity promotion. In A.L. Smith \& S.J.H. Biddle (eds.), Youth Physical Activity and Sedentary Behaviour. Challenges and Solutions (pp. 377-401). Leeds: Human Kinetics.

Fox, K., Cooper, A. \& McKenna, J. (2004) The school and promotion of children's health-enhancing physical activity: Perspectives from the United Kingdom, Journal of Teaching in Physical Education, 23, 336-355.

Fox, K. \& Harris, J. (2003) Promoting physical activity through schools. In J. McKenna \& C. Riddoch (eds.), Perspectives on Health and Exercise (pp.181-201). Basingstoke: Palgrave Macmillan.

Green, K. (2002) Physical education, lifelong participation and the work of Ken Roberts. Sport, Education and Society, 7(2), 167-182.

Green, K. (2009) Exploring the everyday 'philosophies' of physical education teachers from a sociological perspective. In R. Bailey \& D. Kirk (eds.), The Routledge physical education reader (pp. 183-206). London: Routledge Taylor \& Francis.

Green, K., \& Thurston, M. (2002) Physical education and health promotion: A qualitative study of teachers' perceptions. Health Education, 102(3), 113-123.

Hardman, K., \& Marshall, J. (2005) Physical Education in schools in European context: Charter principles, promises and implementation realities. In K. Green \& K. 
Hardman (eds.), Physical Education. Essential Issues (pp. 39-64). London: Sage Publications.

Harris, J. (1997) Physical Education: A Picture of Health? The Implementation of Health-Related Exercise in the National Curriculum in Secondary Schools in England. Unpublished Doctoral thesis, Loughborough University.

Harris, J. (2010). Health-Related Physical Education. In R. Bailey (ed.), Physical Education for Learning: A Guide for Secondary Schools. London: Continuum.

Leggett, G. (2008). A Changing Picture of Health: Health-Related Exercise Policy and Practice in Physical Education Curricula in Secondary Schools in England and Wales. Unpublished doctoral thesis, Loughborough University.

Macdonald, D., \& Hunter, L. (2005) Lessons learned...about curriculum: Five years on and half a world away. Journal of Teaching in Physical Education, 24, 111-126.

McElroy, M. (2008) A Sociohistorical analysis of US youth physical activity and sedentary behaviour. In A.L. Smith \& S.J.H. Biddle (2008) (eds.), Youth Physical Activity and Sedentary Behaviour. Challenges and Solutions (pp. 59-78). Leeds: Human Kinetics.

McKenzie, T., L., \& Lounsbery, M.A.F. (2009). School physical education: The pill not taken. American Journal of Lifestyle Medicine, 3(3), 219-225. Then, 
Miller, M.G., \& Housner, L. (1998) A survey of health-related physical fitness knowledge among pre-service and in-service physical educators. Physical Educator. 55(4), 176-186.

National Institute for Health and Clinical Excellence (NICE). (2007a) Physical Activity and Children. Review 1: Descriptive Epidemiology. NICE Public Health Collaborating Centre: www.nice.org.uk

National Institute for Health and Clinical Excellence (NICE). (2007b) Physical Activity and Children. Review 3: The Views of Children on the Barriers and Facilitators to Participation in Physical Activity: A Review of Qualitative Studies. NICE Public Health Collaborating Centre: www.nice.org.uk

OFSTED (2005). Physical Education in Secondary Schools. London: Author.

OFSTED (2009). Physical Education in Schools 2005/08. Working Towards 2012 and Beyond. London: Author.

Pate, R.R., Trost, S.G., Levin, S. \& Dowda, M. (2000) Sports participation and health-related behaviours among US youth. Archives of Pediatric and Adolescent Medicine, 154, 904-911.

Qualifications and Curriculum Authority. (2007) Physical Education. Programmes of Study. Key Stage 3. Key Stage 4. www.qcda.org.uk/curriculum 
Quick, S., Dalziel, D., Thornton, A. \& Simon, A. (2009). PE and Sport Survey 2008/2009. Research Report No DCSF-RR168. London: Department for Children, Schools and Families.

Salmon, J., Booth, M.L., Phongsavan, P., Murphy, N. \& Timperlo, A. (2007) Promoting physical activity participation among children and adolescents. Epidemiological Reviews, 29, 144-159.

Shephard, R.J. \& Trudeau, F. (2000) The legacy of physical education: Influences on adult lifestyle. Pediatric Exercise Science, 12, 34-50.

Stratton, G., Fairclough, S. \& Ridgers, N. (2008) Physical activity levels during the school day. In A.L. Smith \& S.J.H. Biddle (eds.), Youth Physical Activity and Sedentary Behaviour. Challenges and Solutions (pp. 321-350). Leeds: Human Kinetics.

Stensel, D., Gorely, T., \& Biddle, S. (2008) Youth health outcomes. In: A.L. Smith \& S.J.H Biddle (eds.), Youth Physical Activity and Sedentary Behavior. Challenges and Solutions (pp. 31-57). Leeds: Human Kinetics.

Tinning, R. (2010) Pedagogy and health oriented physical education (HOPE). In R. Tinning. Pedagogy and Human Movement (pp. 169-183). Oxon: Routledge. 
Tinning, R., \& Glasby, T. (2002) Pedagogical work and the 'cult of the body'.

Considering the role of HPE in the context of the 'new public health'. Sport, Education and Society, 7(2), 109-119.

Ward, L. (2009). Physical Education Teachers' Engagement with 'Health-Related Exercise' and Health-Related Continuing Professional Development: A Healthy Profile? Unpublished doctoral thesis, Loughborough University.

Wright, J. (2004). "Being healthy". Critical inquiry and problem solving in physical education. In Wright, J., Macdonald, D. and Burrows, L. (eds.), Critical Inquiry and Problem Solving in Physical Education. London: Routledge. 